\title{
Hypertension among adults in a deprived urban area of Peru - Undiagnosed and uncontrolled?
}

\author{
Alisha R Davies*1, J Jaime Miranda1,2, Robert H Gilman ${ }^{3,4}$ and Liam Smeeth ${ }^{1}$
}

\begin{abstract}
Address: ${ }^{1}$ Department of Epidemiology and Population Health, London School of Hygiene and Tropical Medicine, London, UK, ${ }^{2}$ Facultad de Salud Pública y Administración, Universidad Peruana Cayetano Heredia, Lima, Peru, ${ }^{3}$ Department of International Health, Johns Hopkins Bloomberg School of Public Health, Baltimore, MD, USA and ${ }^{4}$ Laboratorios de Investigación y Desarrollo en Ciencia y Tecnología, Facultad de Ciencias y Filosofía, Universidad Peruana Cayetano Heredia, Lima, Peru
\end{abstract}

Email: Alisha R Davies* - Alisha.Davies@lshtm.ac.uk; J Jaime Miranda - Jaime.Miranda@lshtm.ac.uk; Robert H Gilman - rgilman@jhsph.edu; Liam Smeeth - Liam.Smeeth@lshtm.ac.uk

* Corresponding author

Published: 26 February 2008

BMC Research Notes 2008, I:2 doi:10.1 186/1756-0500-I-2
Received: 31 January 2008

Accepted: 26 February 2008

This article is available from: http://www.biomedcentral.com/I756-0500/I/2

(C) 2008 Davies et al; licensee BioMed Central Ltd.

This is an Open Access article distributed under the terms of the Creative Commons Attribution License (http://creativecommons.org/licenses/by/2.0), which permits unrestricted use, distribution, and reproduction in any medium, provided the original work is properly cited.

\begin{abstract}
Background: In Peru, cardiovascular disease was the second most common cause of death in those aged 65 years or more in 2000. Hypertension is a major modifiable risk factor for cardiovascular disease, and if treated can significantly reduce cardiovascular disease risk. The objectives of this study were to investigate the prevalence of hypertension and levels of awareness, treatment and control in a deprived urban area of Peru.

Methods: A cross-sectional study was completed. Blood pressure measurements were recorded in triplicate. Hypertension was defined as systolic blood pressure $\geq 140 \mathrm{mmHg}$ or diastolic blood pressure $\geq 90 \mathrm{mmHg}$, or self report of receiving antihypertensive medication at the time of interview.

Results: The study sample was 584 adults (29.1\% male, mean age 35.3 years). Age standardized prevalence of hypertension was $19.5 \%(95 \% \mathrm{Cl} 9.9 \%, 29.1 \%)$ in men, $11.4 \%(95 \% \mathrm{Cl} 3.7 \%, 19.1 \%)$ in women, and $13.2 \%(95 \% \mathrm{Cl} 5.0 \%, 21.5 \%)$ overall. Among those with hypertension $38.3 \%(95 \%$ $\mathrm{Cl} 22.7 \%, 53.9 \%, n=18 / 47$ ) were aware of their condition with greater awareness among women than men. Of those aware, $61.1 \%(n=11 / 18)$ were treated, equating to $23.4 \%(95 \% \mathrm{Cl} 10.1 \%$, $36.7 \%, n=11 / 47)$ of all adults with hypertension. Of those treated $63.6 \%(n=7 / 11)$ had controlled hypertension, equating to $14.9 \%(95 \% \mathrm{Cl} 3.0 \%, 26.8 \%, \mathrm{n}=7 / 47)$ of all adults with hypertension.

Conclusion: Levels of awareness and control in this population were low. Lack of control is likely to be due to both a failure to diagnose hypertension, especially among men, and initiate or comply with treatment, especially among women. These results suggest a considerable burden of undiagnosed hypertension, and poor levels of control in those treated, in a deprived urban area of Lima, Peru.
\end{abstract}

\section{Background}

Non-communicable diseases (NCD) are emerging as a major concern for health in developing countries [1]. In
2000, two thirds of all deaths in Latin America and the Caribbean were due to NCDs, with cardiovascular disease (CVD) alone accounting for $31 \%$ of deaths [2]. In Peru, 
CVD was the second most common cause of death in those aged 65 years or more (mortality rate 4 per 1000 population) in 2000. Ischaemic heart disease, heart failure and hypertension are also among the ten most common causes of death reported in this age group [3]. The increasing importance of cardiovascular disease in Latin American has been commented on $[2,4,5]$ and the need for preventative action to be taken to limit, or prevent, a predicted epidemic of cardiovascular disease has been highlighted [6].

Hypertension is a major modifiable risk factor for CVD, and if treated can significantly reduce the risk of CVD. Despite this, many countries, including Europe, America and South Africa, have reported a high proportion of adults with hypertension remain unaware of their condition and fail to be treated [7-11]. Studies investigating hypertension in Peru are scant, with estimates of the prevalence of hypertension range from $16 \%$ to $31 \%$ in men, and $15 \%$ to $23 \%$ in women depending on the population studied [12-15]. In some regions of Peru it has been found that approximately $50 \%$ of adults with hypertension are unaware of their condition and in many their condition is poorly controlled $[12,14]$. In this study, we report the prevalence of hypertension in adults in a deprived urban area of Lima, Peru, and provide information on the diagnosis and treatment of hypertension among this population.

\section{Methods}

In 2001, newborn children were enrolled in a cohort study established for diarrhoeal disease surveillance in San Juan de Miraflores, a deprived urban area of Lima, Peru. This cohort followed similar methodologies to previous diarrhoeal studies carried out by our research group in the same area before $[16,17]$. Enrolled children acted as the index children from which adult family members were invited to participate in a cross-sectional study on hypertension, the results of which are presented in this paper. In 2006, 497 index children were revisited and adult (aged $>17$ years) family members living in the same house as each child were invited to participate in the hypertension study. Informed consent was obtained. No information was recorded on adults who declined to participate. Participating adults were asked if they had ever had a medical diagnosis of hypertension, and if they were prescribed anti-hypertensive medications. Age, height and weight were recorded at interview and the body mass index (BMI) calculated (kilogram per metre ${ }^{2}$ ). BMI was classified as not overweight $(\mathrm{BMI}<25)$, overweight $(25 \leq \mathrm{BMI}<30)$ or obese (BMI $\geq 30$ ). Household bedroom ratio (number of household residents per bedroom) and number of years of education were obtained from the diarrhoeal cohort dataset. Blood pressure (BP) was measured using appropriate cuffs for arm circumference and measurements recorded in triplicate. The BP mean of the last two systolic and diastolic measurements were used in the analysis. Hypertension was defined as systolic blood pressure $(\mathrm{SBP}) \geq 140 \mathrm{mmHg}$ or diastolic blood pressure $(\mathrm{DBP}) \geq$ $90 \mathrm{mmHg}[18,19]$, or self report of receiving antihypertensive medication at the time of interview. Prevalence is the proportion of adults with hypertension and presented as a percentage. Direct standardisation was used to calculate age-standardized prevalence of hypertension by applying age group-specific prevalence (five yearly age groups: $20-24,25-29$ up to $70+$ years) to the World Health Organization standard population [20]. Differences between those with hypertension and without were compared using logistic regression and odds ratios (OR) and their 95\% confidence intervals (CI) are presented. Multiple adults were recruited within a single family unit, and so all analyses were adjusted for the clustering at family unit level. Awareness was defined as the proportion of hypertensive adults reporting a prior medical diagnosis of hypertension or high BP. Controlled hypertension was defined as $\mathrm{SBP}<140 \mathrm{~mm} \mathrm{Hg}$ and DBP $<90 \mathrm{mmHg}$. Ethical approval was granted by the Universidad Peruana Cayetano Heredia ethics committee.

\section{Results}

A total of 584 adults agreed to participate, representing $67.8 \%$ of the families visited (337/497). Only one adult was recruited from 166 family units, and multiple adults were recruited from the remaining 331 families (average number of adults per family unit 1.3 (range 2 to 10)). The majority of the participants $(61.0 \%)$ were parents of the children recruited in the cohort.

Of the 584 (29.1\% male) adults interviewed the mean age was 35.3 years $(95 \%$ CI $34.4,36.3)$. The mean age was 36.7 (95\% CI 34.8, 38.7) years in men and 34.8 (95\% CI $33.7,35.8)$ years in women. Characteristics of the study population are provided in Table 1. Information on BMI was available for 579 adults, $42.1 \%$ of whom were overweight, and $18.2 \%$ obese. A greater proportion of women were obese compared to men (F statistic $=6.4, p=0.002$ ). The majority of adults had some level of education, but a greater proportion of men reported levels of secondary education $(67.1 \%)$ compared to women $(49.0 \%)$.

The mean SBP was $119.3 \mathrm{mmHg}$ (SE 1.0) in men and $109.5 \mathrm{mmHg}$ (SE 0.7) in women. The mean DBP was 74.9 $\mathrm{mmHg}$ (SE 0.8) in men and $68.2 \mathrm{mmHg}$ (SE 0.6) in women (Table 1). A positive correlation between BP and age was found, with a single year increase in age equating to a $0.5 \mathrm{mmHg}(95 \% \mathrm{CI} 0.4,0.6, \mathrm{p}<0.001)$ increase in SBP and a $0.2 \mathrm{mmHg}$ ( $95 \%$ CI $0.1,0.3, \mathrm{p}<0.001)$ increase in DBP. Forty-seven adults had evidence of hypertension, equating to a crude prevalence of $8.0 \%$ (95\% CI 5.8\%, $10.3 \%$ ) in the study population. Hypertension was more 
Table I: Baseline descriptive information, mean and standard error diastolic and systolic blood pressure measurements and hypertension prevalence among adults in San Juan de Miraflores region of Lima, Peru, 2006.

\begin{tabular}{|c|c|c|c|c|}
\hline & $\begin{array}{r}\text { Men } \\
(n=170)\end{array}$ & $\begin{array}{r}\text { Women } \\
(n=4 \mid 4)\end{array}$ & $P$ value & $\begin{array}{r}\text { Total } \\
(n=584)\end{array}$ \\
\hline Age group (n, \%) & & & $0.161^{1}$ & \\
\hline$<30$ years & $49(28.8)$ & $146(35.3)$ & & $195(33.4)$ \\
\hline $30-49$ years & $103(60.6)$ & $237(57.3)$ & & $340(58.2)$ \\
\hline $50+$ years & $18(10.6)$ & $31(7.5)$ & & $49(8.4)$ \\
\hline$B M I(n, \%)$ & & & $0.002^{\prime}$ & \\
\hline Not overweight & $78(45.9)$ & $149(36.0)$ & & 227 (38.9) \\
\hline Overweight & $73(42.9)$ & $173(4 \mid .8)$ & & $246(42.1)$ \\
\hline Obese & $16(9.4)$ & $90(21.7)$ & & $106(18.2)$ \\
\hline Missing & $3(1.8)$ & $2(0.5)$ & & $5(0.9)$ \\
\hline Household bedroom ratio (quartiles) & & & $0.021^{1}$ & \\
\hline I (lowest) & $38(22.4)$ & $81(19.6)$ & & $119(20.4)$ \\
\hline 2 & $29(17.1)$ & $77(18.6)$ & & $106(18.2)$ \\
\hline 3 & $29(17.1)$ & $91(22.0)$ & & $120(20.6)$ \\
\hline 4 (highest) & $65(38.2)$ & $113(27.3)$ & & $178(30.5)$ \\
\hline Missing & $9(5.3)$ & $52(12.6)$ & & $61(10.5)$ \\
\hline Number of years of education & & & $0.005^{\prime}$ & \\
\hline fores & $\mathrm{I}(0.6)$ & $6(1.5)$ & & $7(1.2)$ \\
\hline I to 6 & $27(15.9)$ & $101(24.4)$ & & $128(21.9)$ \\
\hline 7 to 11 & $114(67.1)$ & $203(49.0)$ & & $317(54.3)$ \\
\hline 12 to 21 & $13(7.7)$ & $44(10.6)$ & & $57(9.8)$ \\
\hline Missing & $15(8.8)$ & $60(14.5)$ & & $75(12.8)$ \\
\hline Systolic blood pressure (mmHg, SE) & $119.3(1.0)$ & $109.5(0.7)$ & $<0.001^{2}$ & \\
\hline Diastolic blood pressure (mmHg, SE) & $74.9(0.8)$ & $68.3(0.6)$ & $<0.001^{2}$ & \\
\hline \multicolumn{5}{|l|}{ Prevalence of hypertension $(\%, 95 \% \mathrm{Cl})$} \\
\hline$<30$ years & 0 & $2.7(0.1,5.4)$ & 0.2331 & $2.1(0,4.1)$ \\
\hline $30-49$ years & $14.6(7.6,21.5)$ & $5.9(2.9,8.9)$ & 0.008 & $8.5(5.5,11.6)$ \\
\hline $50+$ years & $27.8(6.0,49.5)$ & $29.0(12.1,46.0)$ & 0.9271 & $28.6(16.2,4 \mid .0)$ \\
\hline Crude (all ages) & $11.8(6.9,16.7)$ & $6.5(4.1,8.9)$ & $0.036 !$ & $8.0(5.8,10.3)$ \\
\hline Age standardized ${ }^{3}$ ( 20 to $70+$ years) & $19.5(9.9,29.1)$ & $11.4(3.7,19.1)$ & $0.674^{2}$ & $13.2(5.0,2 \mid .5)$ \\
\hline
\end{tabular}

Icluster design based $\mathrm{p}$ value from $\mathrm{F}$ statistic; ${ }^{2} \mathrm{z}$ test; ${ }^{3}$ Standardized to the World Health Organization world population standard; SE standard error; Cl confidence interval.

prevalent in men compared with women, and increased with increasing age group (Table 1). Age standardized prevalence of hypertension was $13.2 \%$ (95\% CI $5.0 \%$, $21.5 \%)$, and greater in men $(19.5 \%$ (95\% CI $9.9 \%$, $29.1 \%)$ ) than women (11.4\% (95\% CI 3.7\%, 19.1\%)). Among those with untreated hypertension the predominant type of hypertension was isolated diastolic hypertension $(42.5 \%, 17 / 40)$ compared to isolated systolic hypertension $(27.5 \%, 11 / 40)$ and systodiastolic hypertension $(30.0 \%, 12 / 40)$.

The crude odds of hypertension in men were twice that found in women (Table 2), but after adjusting for explanatory factors in the multivariate analysis no evidence of a sex difference in the prevalence of hypertension remained. In the crude logistic regression there was some evidence to suggest that the odds of hypertension were greater in those overweight or obese, and in those with no education, however these associations were not found in the multivariate analysis (Table 2). There was strong evidence of an increasing odds of hypertension with increasing age, and this remained after adjustment for other explanatory factors (Table 2).

Only one third (38.3\% (95\% CI 22.7\%, 53.9\%)) of all hypertensive adults were aware of their condition (Figure 1 ). There was evidence to suggest a greater proportion of women (55.6\% (95\% CI 34.9\%, 76.2\%), $\mathrm{n}=15 / 27)$ were aware of their hypertension, compared to men $(15.0 \%$ $(95 \%$ CI $-2.1 \%, 32.1 \%), \mathrm{n}=3 / 20)(\mathrm{F}$ statistic $=8.5, \mathrm{p}$ value $=0.006)$. A trend of increasing awareness with decreasing household bedroom ratio, an indicator of socio-economic status, was found (F statistic $=2.8, \mathrm{p}=$ $0.042)$. There was no evidence to suggest a difference in awareness with age ( $F$ statistic $=0.9, \mathrm{p}=0.419)$, and no evidence of greater awareness in the obese compared to the non-obese (F statistic $=3.1, \mathrm{p}=0.084)$. Among adults aware of their hypertension $61.1 \%$ (95\% CI $36.3 \%$, $85.9 \%, \mathrm{n}=11 / 18)$ reported receiving anti-hypertensive medication, equating to $23.4 \%$ (95\% CI 10.1\%, 36.7\%, n $=11 / 47$ ) of all adults with hypertension (Figure 1). Although the numbers are small there was some evidence 
Table 2: Crude and adjusted odds ratio for risk factors for hypertension among adults in San Juan de Miraflores region of Lima, Peru, 2006.

\begin{tabular}{|c|c|c|c|c|}
\hline & \multicolumn{2}{|l|}{ Crude } & \multicolumn{2}{|c|}{ 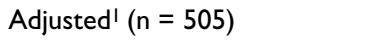 } \\
\hline & $\begin{array}{r}\text { Odds ratio } \\
(95 \% \mathrm{Cl})\end{array}$ & $P$ value & $\begin{array}{l}\text { Odds ratio } \\
(95 \% \mathrm{Cl})\end{array}$ & $P$ value \\
\hline \multicolumn{5}{|l|}{ Sex } \\
\hline Female & 1 & & I & \\
\hline Male & $1.9(1.0,3.5)$ & 0.038 & $1.7(0.8,3.3)$ & 0.135 \\
\hline \multicolumn{5}{|l|}{ Age group } \\
\hline$>30$ years & 1 & & I & \\
\hline $30-49$ years & $4.5(1.6,12.7)$ & 0.005 & $4.5(1.3,15.4)$ & 0.018 \\
\hline $50+$ years & $19.1(6.1,60.2)$ & $<0.001$ & $18.9(4.9,73.1)$ & $<0.001$ \\
\hline \multicolumn{5}{|l|}{$B M I$} \\
\hline Not overweight & 1 & & I & \\
\hline Overweight & $2.5(1.2,5.2)$ & 0.018 & $1.9(0.8,4.7)$ & 0.138 \\
\hline Obese & $2.3(0.9,5.7)$ & 0.085 & $2.2(0.8,6.1)$ & 0.133 \\
\hline \multicolumn{5}{|c|}{ Household bedroom ratio (quartiles) } \\
\hline I (lowest) & I & & I & \\
\hline 2 & $0.7(0.3,1.7)$ & 0.439 & I.I $(0.4,2.6)$ & 0.880 \\
\hline 3 & $0.5(0.2,1.2)$ & 0.102 & $0.7(0.2,1.7)$ & 0.395 \\
\hline 4 (highest) & $0.4(0.2,1.0)$ & 0.049 & $0.6(0.2,1.4)$ & 0.222 \\
\hline \multicolumn{5}{|c|}{ Number of years of education } \\
\hline 0 & $11.0(1.2,98.4)$ & 0.032 & I.I (0.I, 2 I.7) & 0.936 \\
\hline I to 6 & $2.6(0.6,12.4)$ & 0.234 & $1.8(0.3,9.4)$ & 0.499 \\
\hline 7 to 11 & $2.5(0.5,11.0)$ & 0.238 & $2.3(0.5,11.3)$ & 0.311 \\
\hline 12 to 21 & । & & । & \\
\hline
\end{tabular}

I adjusted for all other variables listed in the table; $\mathrm{Cl}$ confidence interval. Adjusted for clustering.

of a sex difference in the treatment of hypertension, with only $53.3 \%$ (95\% CI $26.4 \%, 80.2 \%, \mathrm{n}=8 / 15)$ of the women aware of their hypertension receiving treatment, compared to all of the men $(100 \%, \mathrm{n}=3 / 3)$. Among treated, 63.6\% (95\% CI 27.3\%, 100.0\%, $\mathrm{n}=7 / 11)$ had controlled hypertension, equating to only $14.9 \%$ (95\% CI $3.0 \%, 26.8 \%, \mathrm{n}=7 / 47$ ) of all adults with hypertension.

\section{Discussion}

In our study, we report the age standardised prevalence of hypertension among young adults in a deprived urban area of Lima was $13.2 \%$ (95\% CI 5.0\%, 21.5\%). Overall, $38 \%$ (95\% CI 22.7\%, 53.9\%) of all adults with hypertension were aware of their diagnosis, $23 \%$ (95\% CI $10.1 \%$, $36.7 \%$ ) were receiving treatment, and control was achieved in only $15 \%$ (95\% CI 3.0\%, 26.8\%) of hypertensive adults.

\section{Comparison with other studies}

The crude prevalence of hypertension found in this study $(8.0 \%$ (95\% CI 5.8\%, 10.3\%)) was lower than that reported by other studies in Peruvian populations and this is likely to reflect the young age of our study population [12-15]. A cross-sectional study of the adult population in Peru by the Peruvian Society of Cardiology reported a national prevalence of $23.7 \%$ (men $27.1 \%$, women $20.4 \%$ ), but prevalence was lower $(15.3 \%)$ in the south of Lima, the geographical region most comparable to our study [12]. More robust estimates of prevalence are available from the PREVENCION study carried out in a large city in the mountainous regions of Peru. The prevalence of hypertension found among a representative population of adults with an older mean age that our study population (49.1 compared to 35.3 years) was $15.7 \%$ (95\% CI 14.0 to $17.4 \%$ ) [14].

\section{Awareness}

We found that $38 \%$ of adults with hypertension were aware of their condition, and awareness was much greater in women compared to men. Similar levels of awareness, and supporting evidence of a sex difference in awareness, have been reported by other studies in Peru $[12,14]$. Awareness in Peru is low compared to international estimates, for example a study in Sao Paulo, Brazil, reported three quarters of those with hypertension were aware of their condition [21]. A review of hypertension in national representative population surveys completed in the 1990s reported the awareness among the adult (35 to 64 years) population was $69 \%$ in America, 63\% in Canada, and ranged from 36 to $52 \%$ in five European countries $[11,22]$. 


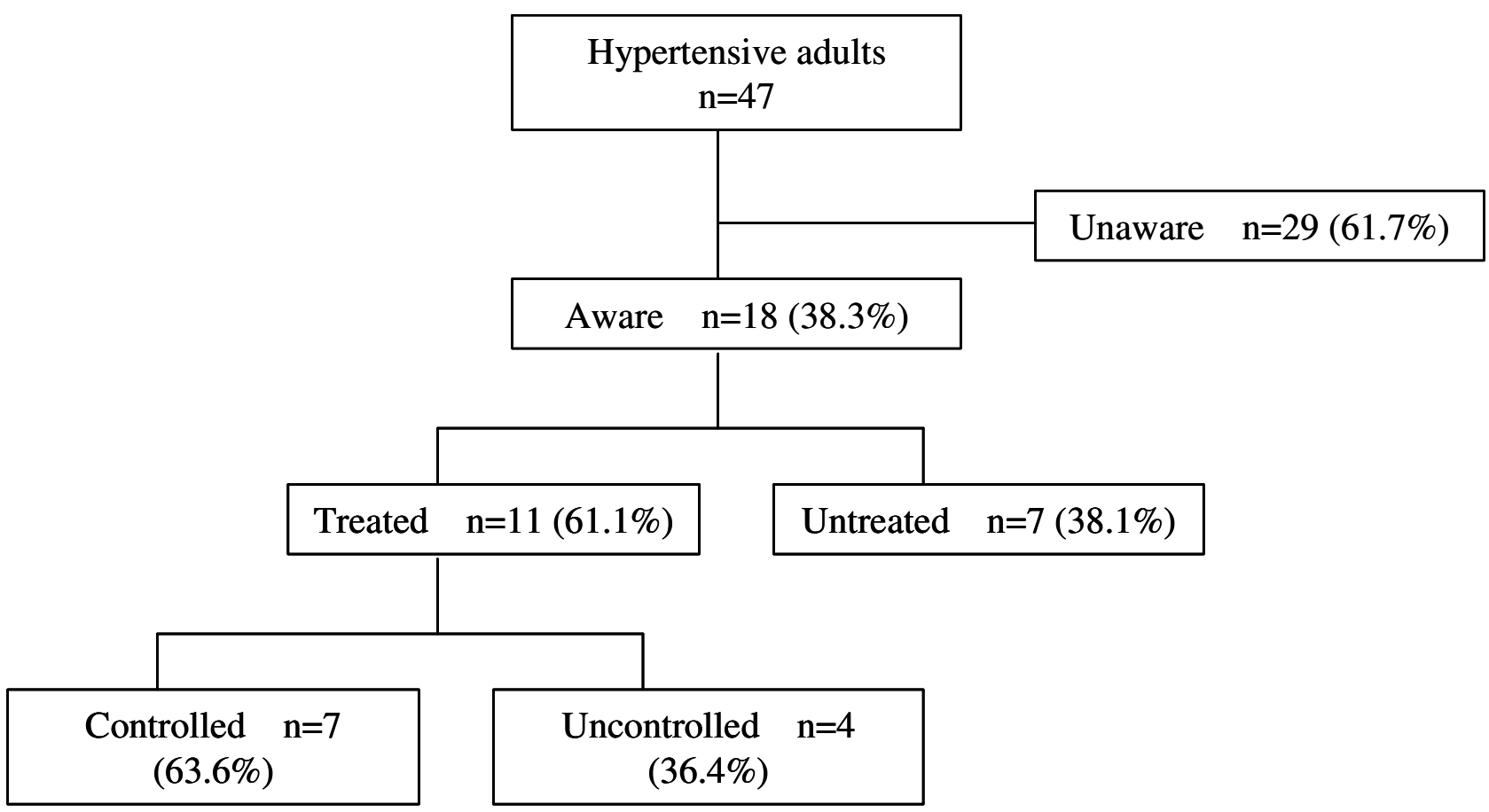

Figure I

The proportion awareness, treatment and control among hypertensive adults in San Juan de Miraflores region of Lima, Peru, 2006.

\section{Controlled hypertension}

In our study population only $23 \%$ of those with hypertension were receiving pharmaceutical treatment and hypertension control was achieved in two thirds of those treated. These estimates are comparable to that reported by the PREVENCION study (39.5\% treated, 35.7\% controlled among those treated) [14] and the national survey (28.1\% treated, $23.6 \%$ controlled among those treated) [12]. Treatment levels in Peru are much lower than in America (53\%), Canada (36\%), Europe (25 to 60\%) and Brazil (62\%) [11,21-23]. The lower treatment rates found in Peru may be due to social and cultural differences, for example adults tend to attend a doctor or take medication only if they feel ill. This may result in low diagnosis rates and reduce the opportunity to provide treatment and advice on the importance of compliance. In addition, there are economic factors to consider as adults must pay for prescribed medications in Peru.

Among those aware of their hypertension we found evidence to suggest women were less likely to be treated than men. This may be due to the small numbers investigated, as no sex difference in treatment was found in the PREVENCION study [14]. However, it may also reflect gender differences in access to treatment despite being aware of their condition. Further investigation is needed to determine if there is a true sex difference in treatment among this poor population, and if so, to explore the possible underlying reasons. Encouragingly we found hypertension was controlled in two thirds of the adults treated, which is comparable to other developed countries. However, this equates to achieving control in only $15 \%$ of all adults with hypertension, which is comparable to that reported in other areas of Peru $[12,14]$. Lack of control among our study population is likely to be due to both a failure to diagnose hypertension, especially among men, and initiate or comply with treatment, especially among women. Over time, as the patient ages, uncontrolled hypertension can result in more severe cardiovascular problems. To find this level of uncontrolled hypertension among a relatively young population is of cause for concern, as the detrimental effects on health will increase as the population ages.

\section{Strengths and weaknesses}

This is a descriptive observational study and, as such, has a number of limitations. A possible sampling bias, due to the selection of adults from families who had already 
agreed to their child participating in a diarrhoeal follow up cohort, could be expected. However, the initial birth cohort was randomly selected and as being born in a community is a random process, and family members of each child were invited to participate based on these index children, the adults in this hypertension study may be considered a quasi-random sample of adults from the area of San Juan de Miraflores, Lima, Peru. Only a small number of patients with hypertension were identified, and as a result of the small sample size the estimates of hypertension awareness, treatment and control may not be robust and should be considered with caution. A further limitation of the small study sample was that men were under-represented, accounting for less than one third of the adults interviewed, and as a result the confidence interval for the estimate of hypertension prevalence among men was wide. The aim of our study was not to investigate sex differences in awareness, treatment and control, and therefore such findings should be treated with caution. The study design meant that some individuals were recruited from the same family units, or clusters. One consideration of this type of data is that individuals recruited from the same family units (or clusters) are likely to be more similar to each other than to individuals from different families. However, the extent of clustering was minimal (one adult was recruited from 166 family units, and in the remaining 331 family units (clusters) the average number of adults recruited from each cluster was 1.3). Further adjustment for clustering did not affected the point estimates of prevalence and treatment and awareness, and only had a limited effect on the confidence intervals, e.g. the crude prevalence of hypertension unadjusted for clustering was $8.0 \%(95 \%$ CI $5.8 \%, 10.3 \%)$ and after adjustment for clustering the confidence interval remained $5.8 \%$ to $10.3 \%$ due to the very small change to the standard error. A further limitation of this study is that the estimates of awareness are subject to recall bias, as an individual's awareness of hypertension was based on selfreport. Finally, although the BP measurements were completed in triplicate, they were taken only on one day and it is recommended that a diagnosis of hypertension in adults be made by multiple BP measurements recorded on separate occasions [19].

\section{Conclusion}

Hypertension is a major modifiable risk factor and if left uncontrolled it can result in major cardiovascular problems in later life.Although this study is small and has a number of limitations it does raise some important questions about the provision of care and treatment for patients with hypertension in a deprived urban area of Peru. The results, along with that from other published studies indicate a large burden of undiagnosed hypertension in the population of Peru, and poor levels of control. This set within the context a country with underlying dif- ficulties in the provision of health care represents a great challenge for public health in Peru.

\section{Competing interests}

The authors declare that they have no competing interests.

\section{Authors' contributions}

JJM conceived the study design, was responsible for the data collection, contributed to the data analysis and writing the paper. ARD completed analyses, interpreted findings, and was the principal author of the manuscript. RHG and LS were involved in the study design, and contributed to the interpretation of data, and editing the paper.

\section{Acknowledgements}

This work was funded by the Royal Society of Tropical Medicine and Hygiene through a Dennis Burkitt Fellowship to JJM. ARD is supported by the Economic and Social Research Council. JJM is supported by a Wellcome Trust Research Training Fellowship (GR074833MA). Our gratitude to all staff and fieldworkers who contributed to this study, and most importantly, to families who took part in the study.

\section{References}

I. World Health Organization: Preventing Chronic Diseases: A Vital Investment. Geneva , World Health Organization; 2005:196.

2. Perel P, Casas JP, Ortiz Z, Miranda JJ: Noncommunicable Diseases and Injuries in Latin America and the Caribbean: Time for Action. PLoS Medicine 2006, 3(9):e344.

3. Ministeriod de Salud: Informacion de mortalidad. Lima, Peru , Ministeriod de Salud; 2007.

4. Yusuf S, Vaz M, Pais P: Tackling the challenge of cardiovascular disease burden in developing countries. Am Heart J 2004, I 48(I): I-4.

5. Yusuf S, Reddy S, Ounpuu S, Anand S: Global Burden of Cardiovascular Diseases: Part I: General Considerations, the Epidemiologic Transition, Risk Factors, and Impact of Urbanization. Circulation 200I, 104(22):2746-2753.

6. Medina-Lezama MD, Chirinos-Pacheco JMD, Chirinos JA: Cardiovascular disease in Latin America . Am Heart J 2005, I49(2): EI3.

7. Hajjar I, Kotchen TA: Trends in Prevalence, Awareness, Treatment, and Control of Hypertension in the United States, 1988-2000. JAMA 2003, 290(2): 199-206.

8. Fagard $\mathrm{RH}$, Van den Enden $M$, Leeman $M$, Warling $X$ : Survey on treatment of hypertension and implementation of World Health Organization/International Society of Hypertension risk stratification in primary care in Belgium. J Hypertens 2002, 20(7): I 297-I302.

9. Steyn K, Gaziano TA, Bradshaw D, Laubscher R, Fourie J, for the South African Demographic and Health Coordinating Team: Hypertension in South African adults: results from the Demographic and Health Survey, 1998. J Hypertens 200I, I9(10): I717-1725.

10. van Rossum CTM, van de Mheen $\mathrm{H}$, Witteman JCM, Hofman A, Mackenbach JP, Grobbee DE: Prevalence, Treatment, and Control of Hypertension by Sociodemographic Factors Among the Dutch Elderly. Hypertension 2000, 35(3):814-82I.

II. Scheltens T, Bots ML, Numans ME, Grobbee DE, Hoes AW: Awareness, treatment and control of hypertension: the 'rule of halves' in an era of risk-based treatment of hypertension. J Hum Hyperten 2007, 2 I:99-106.

12. Vega LS, Agusti R, Ramirez JP, and the investigators of the Tornasol Study: Factores de riesgo de las enfermedades cardiovasculares en el Peru (Estudio TORNASOL). Revista Peruana de Cardiología 2006, XXXII(2):82-128.

13. Lopez de Guimaraes D, Chiriboga Garcia MR, Gonzales Crisostomo GP, Vega Mejia VC: Prevalencia de algunos factores de riesgo cardiovascular en dos poblaciones de Hauraz $(3,100 \mathrm{~m}$ sobre en nivel del mar). Acta Med Per 2007, 24(I): |8-2I. 
14. Medina-Lezama J, Zea-Diaz H, Morey-Vargas OL, Bolanos-Salazar JF, Postigo-Macdowall M, Paredes-Diaz S, Corrales-Medina F, ValdiviaAscuna Z, Cuba-Bustinza C, Villalobos-Tapia P, Munoz-Atahualpa E, Chirinos-Pacheco J, Raij L, Chirinos JA: Prevalence and patterns of hypertension in Peruvian Andrean Hispanics: The PREVENCION study. J Am Soc Hypertens 2007, I (3):2 I6-225.

15. Seclen S, Leey J, Villena A, Herrera B, Menacho J, Carrasco A, Vargas R: Prevalencia de Obesidad, Diabetes Mellitus, Hipertension, Arterial e Hipercolesterolemia como Factores de Riesgo Coronario y Cerebrovascular en Poblacion Adulta do la Costa, Sierra y Selva del Peru. Acta Med Per 1999, 17:8-12.

16. Checkley W, Epstein LD, Gilman RH, Cabrera L, Black RE: Effects of Acute Diarrhea on Linear Growth in Peruvian Children. Am J Epidemiol 2003, I57(2): 166-175.

17. Checkley W, Gilman RH, Black RE, Epstein L, Cabrera L, Sterling C, Moulton L: Effect of water and sanitation on childhood health in a poor Peruvian peri-urban community. Lancet 2004, 363(9403): I I2-II8.

18. Chobanian AV, Bakris GL, Black HR, Cushman WC, Green LA, Izzo JL, Jones DW, Materson BJ, Oparil S, Wright JT, Roccella EJ: The Seventh Report of the Joint National Committee on Prevention, Detection, Evaluation, and Treatment of High Blood Pressure: the JNC 7 report. JAMA 2003, 289:2560-2572.

19. Mancia G, De Backer G, Dominiczak A, Cifkova R, Fagard R, Germano G, Grassi G, Heagerty AM, Kjeldsen SE, Laurent S, Narkiewicz K, Ruilope L, Rynkiewicz A, Schmieder RE, Struijker Boudier HAJ, Zanchetti A, E. S. C. Committee for Practice Guidelines, Vahanian A, Camm J, De Caterina R, Dean V, Dickstein K, Filippatos G, FunckBrentano C, Hellemans I, Kristensen SD, McGregor K, Sechtem U, Silber S, Tendera M, Widimsky P, Zamorano JL, Council ESHS, Kjeldsen SE, Erdine S, Narkiewicz K, Kiowski W, Agabiti-Rosei E, Ambrosioni E, Cifkova R, Dominiczak A, Fagard R, Heagerty AM, Laurent S, Lindholm LH, Mancia G, Manolis A, Nilsson PM, Redon J, Schmieder RE, Struijker-Boudier HAJ, Viigimaa M, Document R, Filippatos G, Adamopoulos S, Agabiti-Rosei E, Ambrosioni E, Bertomeu V, Clement D, Erdine S, Farsang C, Gaita D, Kiowski W, Lip G, Mallion JM, Manolis AJ, Nilsson PM, O'Brien E, Ponikowski P, Redon J, Ruschitzka F, Tamargo J, van Zwieten P, Viigimaa M, Waeber B, Williams B, Zamorano JL: 2007 Guidelines for the management of arterial hypertension: The Task Force for the Management of Arterial Hypertension of the European Society of Hypertension (ESH) and of the European Society of Cardiology (ESC). Eur Heart J 2007, 28(I 2): I 462-1536.

20. World Health Organization: WHO World Standard population - [http://www.who.int/infobase/help.aspx?helpid=293]

21. Freitas OC, Carvalho FR, Neves JF, Veludo PK, Parreira RS, Gonçalves RM, Lima SA, Bestetti RB: Prevalence of Hypertension in the Urban Population of Catanduva, in the State of São Paulo, Brazil. Arq Bras Cardiol 200I, 77:16-21.

22. Wolf-Maier K, Cooper RS, Kramer H, Banegas JR, Giampaoli S, Joffres MR, Poulter N, Primatesta P, Stegmayr B, Thamm M: Hypertension Treatment and Control in Five European Countries, Canada, and the United States. Hypertension 2004, 43(I): I0-17.

23. Boersma E, Keil U, De Bacquer D, Pyorala K, Poldermans D, Leprotti C, Pilotto L, de Swart E, Deckers JW, Heidrich J, Sans S, Kotseva K, Wood D, Ambrosio GB, EUROASPIRE I and II Study Groups: Blood pressure is insufficiently controlled in European patients with established coronary heart disease. J Hypertens 2003, 2I(10): $|83|-1840$.
Publish with Bio Med Central and every scientist can read your work free of charge

"BioMed Central will be the most significant development for disseminating the results of biomedical research in our lifetime. "

Sir Paul Nurse, Cancer Research UK

Your research papers will be:

- available free of charge to the entire biomedical community

- peer reviewed and published immediately upon acceptance

- cited in PubMed and archived on PubMed Central

- yours - you keep the copyright
BioMedcentral 